\title{
Echinoderm model systems, homology, and phylogenetic inference: Comment and reply to Paul (2021)
}

\author{
Jennifer E. Bauer, Sarah L. Sheffield, Johnny A. Waters, and Colin D. Sumrall \\ Acta Palaeontologica Polonica 67 (2), 2022: 465-468 doi:https://doi.org/10.4202/app.00956.2021
}

Understanding the phylogenetic relationship among derivedblastozoans has been a goal of researchers since phylogeneticmethodologies were first applied to Paleozoic echinoderms.Paul (2021) proposed a new "pan-dichoporites"group to circumscribe early Paleozoic blastozoans. Unfortunately, this work includes many inaccuracies, non-reproducibleanalyses, and nonstandard method choices that confuserather than advance the understanding of echinodermpaleobiology. Herein, we focus on key aspects of philosophy,methodology, and data reproducibility the publication ofPaul (2021) raises that need to be addressed and consideredby echinoderm researchers as they assess the concept ofpan-dichoporite echinoderms.

Jennifer E. Bauer [bauerjen@umich.edu], University of Michigan Museum of Paleontology, 1105 North University Ave., Ann Arbor, MI 48109 USA. Sarah L. Sheffield [ssheffield2@usf.edu], 4202 E. Fowler Ave, NES 102, Tampa FL, 33620, USA. Johnny A. Waters [watersja@appstate.edu], Department of Geological and Environmental Sciences, Appalachian State University, 033 Rankin Science West, ASU Box 32067 Boone, NC 28608-2067, USA. Colin D. Sumrall [csumrall@utk.edu], Department of Earth and Planetary Sciences, The University of Tennessee, 1621 Cumberland Avenue, 602 Strong Hall, Knoxville, TN 37996-1526, USA.

This is an open-access article distributed under the terms of the Creative Commons Attribution License (for details please see creativecommons.org), which permits unrestricted use, distribution, and reproduction in any medium, provided the original author and source are credited. 
